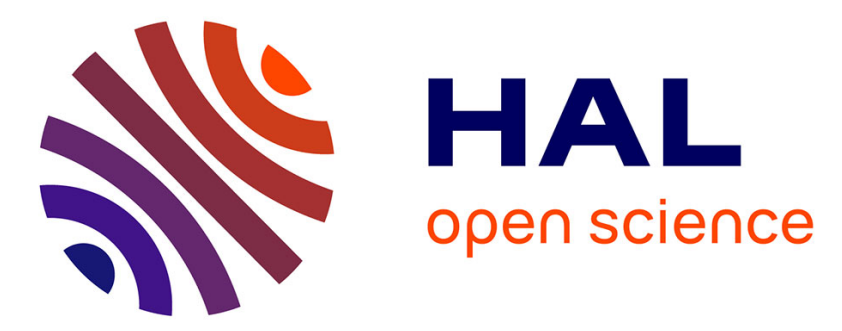

\title{
Comparison of Commercial and Lab-made MWCNT Buckypaper: Physicochemical Properties and Bioelectrocatalytic O 2 Reduction
}

Xiaohong Chen, Andrew Gross, Fabien Giroud, Michael Holzinger, Serge Cosnier

\section{To cite this version:}

Xiaohong Chen, Andrew Gross, Fabien Giroud, Michael Holzinger, Serge Cosnier. Comparison of Commercial and Lab-made MWCNT Buckypaper: Physicochemical Properties and Bioelectrocatalytic O 2 Reduction. Electroanalysis, 2018, 30 (7), pp.1511-1520. hal-02007116

\author{
HAL Id: hal-02007116 \\ https://hal.science/hal-02007116
}

Submitted on 19 Nov 2020

HAL is a multi-disciplinary open access archive for the deposit and dissemination of scientific research documents, whether they are published or not. The documents may come from teaching and research institutions in France or abroad, or from public or private research centers.
L'archive ouverte pluridisciplinaire HAL, est destinée au dépôt et à la diffusion de documents scientifiques de niveau recherche, publiés ou non, émanant des établissements d'enseignement et de recherche français ou étrangers, des laboratoires publics ou privés. 


\title{
Comparison of Commercial and Lab-Made MWCNT Buckypaper: Physicochemical Properties and Bioelectrocatalytic $\mathrm{O}_{2}$ Reduction
}

\author{
Xiaohong Chen, ${ }^{[a, b]}$ Andrew J. Gross, ${ }^{[a, b]}$ Fabien Giroud,,${ }^{[a, b]}$ Michael Holzinger, ${ }^{[a, b]}$ and Serge Cosnier*[a,b]
}

\begin{abstract}
Buckypapers have emerged as an important material for the construction of enzyme-based electrodes and biofuel cells for energy harvesting. In this work, commercial and lab-made buckypapers have been compared to establish their properties for future use as advanced bioelectrodes. The physical properties of the paper-like carbon nanotube films were characterised by electron microscopy, four-point probe conductivity, X-ray photoelectron spectroscopy and Raman spectroscopy. The electrochemical properties were investigated by voltammetry in the absence and presence of redox probes. Bioelectrocatalytic oxygen reduction was evaluated with iron-protoporphyrin modified buckypapers after immobilisation of bilirubin oxidase. Lab-made buckypaper ex-
\end{abstract}

hibited a wider potential window, lower background capacitance, and cleaner voltammetry compared to commercial buckypaper. The catalytic current of lab-made buckypaper was 10-fold larger due to factors which include the 10-fold larger BET surface area, higher enzyme loading, more defective structure, and the smaller nanotube diameters. The presence of porphyrin groups enhanced the catalytic current in $\mathrm{O}_{2}$-saturated solution up to $0.5 \mathrm{~mA} \mathrm{~cm}^{-2}$ and $1.3 \mathrm{~mA} \mathrm{~cm}^{-2}$ for commercial and labmade buckypaper, respectively. This work sheds new light on the effects of various physicochemical properties on the electrochemical and DET-type bioelectrocatalytic activity of buckypapers, and promises to be important for the development of bioelectronics devices.

Keywords: Bucky paper electrode $\cdot$ bioelectrocatalysis $\cdot$ enzyme $\cdot$ energy harvesting $\bullet$ bioelectrode

\section{Introduction}

Nanostructured carbon materials such as carbon nanotubes (CNTs) and templated mesoporous carbons have shown great promise as electrodes for enzymatic bioelectrocatalysis for applications including biosensors and biofuel cells [1-5]. CNT-based electrodes are attractive for bioelectrocatalysis owing to their properties such as high conductivity, large specific surface area, exceptional mechanical strength, and the ability to undergo efficient electron transfer with oxidoreductase enzymes [6,7]. CNT electrodes also benefit from being readily modified with surface functionalities via covalent and non-covalent methods, for example, to enhance the electrical "wiring" and stabilisation of enzymes for bioelectrocatalysis [8-10]. Non-covalent surface modification based on pi-pi stacking of pyrene derivatives and other polyaromatics on nanotube sidewalls is a convenient strategy which retains the extended pi-conjugation of CNT networks and hence their electrical conductivity [10-14].

Buckypaper (BP) is a very attractive type of CNT material which has emerged in recent years for the construction of bioanodes and biocathodes for use in enzymatic biofuel cells [13-19]. Commercial buckypaper has been used in actual implanted devices since 2012, most notably, for in-vivo biofuel cells and electronic device powering $[16,18,20,21]$. $\mathrm{BP}$ is a randomly ordered self-supporting film of carbon nanotubes which is typically formed by vacuum filtration of aqueous and non-aqueous dispersions of CNTs $[15,22,23]$. The films are microscalethin $(c a .5$ to $300 \mu \mathrm{m})$ and held together by pi-pi stacking and interweaving interactions [23,24]. Unlike classical CNT electrodes, which are formed by depositing CNT films on conductive glassy carbon and metal substrates, buckypapers are the electrode itself. Buckypaper electrodes are convenient to fabricate in the lab or can be obtained from commercial sources $[15,18]$. However, their electronic and physicochemical properties are strongly dependent on factors such as the type of CNTs used (e.g. length, diameter, quantity, defects and purity), dispersion homogeneity, the presence of additives and the solvents used, which create challenges concerning reproducibility and functionality.

For the construction of biocathodes, multicopper oxidases (MCOs) such as bilirubin oxidase (BOx) and laccase are typically employed as the biocatalyst for the four-electron reduction of $\mathrm{O}_{2}$ to $\mathrm{H}_{2} \mathrm{O}$ [25]. These enzymes possess four $\mathrm{Cu}$ atoms with the $\mathrm{T} 1 \mathrm{Cu}$ centre, responsible

[a] X. Chen, A. J. Gross, F. Giroud, M. Holzinger, S. Cosnier Univ. Grenoble Alpes, CNRS, DCM UMR 5250, 38000 Grenoble, France

E-mail: serge.cosnier@univ-grenoble-alpes.fr

[b] X. Chen, A. J. Gross, F. Giroud, M. Holzinger, S. Cosnier CNRS, DCM UMR 5250, F-38000 Grenoble, France

Supporting information for this article is available on the WWW under https://doi.org/10.1002/elan.201800136 
for substrate oxidation and successive electron transfers, located near the protein surface, and a tri-nuclear cluster of $\mathrm{T} 2 / \mathrm{T} 3 \mathrm{Cu}$ centres which is more deeply buried [26]. There is therefore great interest in the development of electrode-enzyme interfaces which permit the efficient orientation and electrical connection of the $\mathrm{T} 1 \mathrm{Cu}$ centre.

Hussein and coworkers developed the first buckypaper biocathodes (lab-made) by adsorption of inks containing either BOx or laccase, ABTS mediator, and Nafion $[23,27]$. A maximum current density up to $0.7 \mathrm{~mA} \mathrm{~cm}^{-2}$ in oxygen-saturated buffer was achieved via mediated electron transfer (MET) [27]. Atanassov and coworkers developed air-breathing electrodes by fusing commercial buckypaper with Toray paper and a carbon black gas diffusion layer [28]. This approach is attractive for enhancing the mass transport of oxygen from air to the electrode surface, thus helping to address the limited oxygen supply in quiescent aqueous solutions. The best performing biocathode, based on direct electron transfer (DET) with BOx, delivered a current output of $c a$. $0.7 \mathrm{~mA} \mathrm{~cm}^{-2}$ in buffer solution with capillary flow [28]. Pankratov et al. later reported the simple adsorption of BOx on different lab-made BP samples without the use of Nafion as a binder [29]. DET-type bioelectrocatalysis for oxygen reduction was demonstrated but currents only up to $100 \mu \mathrm{A} \mathrm{cm}^{-2}$ were achieved, implying limited catalytic activity of the nanotubes and a low enzyme loading.

Scherbahn et al. demonstrated that pyrroloquinoline quinone (PQQ) can be used as an orientation promoter for DET with BOx on commercial buckypaper [14]. PQQ was effectively adsorbed on the electrode via pi-pi stacking interactions and gave a 5-fold increase in catalytic currents up to $0.97 \mathrm{mAcm}^{-2}$ in buffer solution compared to the simple adsorption of $\mathrm{BOx}$ on unmodified electrodes. Minteer and coworkers developed lab-made buckypapers modified with a pyrene-anthracene for oriented DET with BOx [19]. Although low catalytic currents of $c a$. $100 \mu \mathrm{A} \mathrm{cm}^{-2}$ were observed, this work demonstrated that buckypaper can be an excellent material for the construction of wearable contact-lens bioelectrodes. We have also demonstrated the use of an orientation promoter, protoporphyrin, to enhance DET with BOx on buckypaper [15]. Well-defined voltammetry and high limiting currents up to $1.33 \mathrm{mAcm}^{-2}$ were observed in oxygen-saturated buffer with purging, highlighting the promising electrochemical and catalytic performance of these lab-made buckypapers.

Buckypaper is now an important electrode material for the development of enzymatic biocathodes, yet little attention has been given to establishing their electrochemical and physicochemical properties and how these properties influence DET bioelectrocatalysis. The reported studies have until now focused on the development of reliable fabrication methods and enzyme wiring strategies to improve catalytic outputs in-vivo and in-vitro.

We report here a comparative study which establishes a baseline for the electrochemical properties of two prominent types of buckypaper: a commercial buckypaper from an established source, NanoTechLabs Inc. (Buckeye Composites), and a recently reported lab-made buckypaper with promising electrode properties [15]. In addition, this study compares the physicochemical properties and the bioelectrocatalytic oxygen reduction activity of unmodified and iron-protoporphyrin modified buckypapers with immobilised $\mathrm{BOx}$.

\section{Experimental}

\subsection{Materials and Reagents}

Potassium phosphate dibasic, potassium phosphate monobasic, N,N-dimethylformamide (DMF, 99.9\%), hexaammineruthenium (III) chloride $\left(\mathrm{Ru}\left(\mathrm{NH}_{3}\right)_{6}, 98 \%\right)$, hemin (iron-protoporphyrin, $\geq 97 \%$ ), potassium hexacyanoferrate(III) $\left(\mathrm{Fe}(\mathrm{CN})_{6}, \geq 99.0 \%\right)$ and sulfuric acid $(95-97 \%)$ were purchased from Sigma-Aldrich. Ferrocenemethanol (FcMeOH, 97\%) was purchased from Acros Organics. Iron (II) sulfate heptahydrate $(\geq 99.0 \%)$ was purchased from Prolabo. Bilirubin oxidase (BOx) from Myrothecium verrucaria (E.C. 1.3.3.5, estimated activity: $8.36 \mathrm{U} \mathrm{mg}^{-1}$ [30]) was purchased from Amano Enzyme. Commercial MWCNT proprietary blend buckypaper (c-BP) with reference number NTL-12218 was obtained from NanoTechLabs, Inc. Multi-walled carbon nanotubes (MWCNTs) $(\varnothing=9.5 \mathrm{~nm}$, purity $>95 \%, 1.5 \mu \mathrm{m}$ length) were obtained from Nanocyl and used for lab-made buckypaper (1-BP) fabrication. Distilled deionized water (15 M $\Omega$ ) was obtained from an ELGA PURELAB purification system. Oxygen and argon were purchased from Air Liquide (France). Potassium phosphate buffer (PB) was prepared from potassium phosphate dibasic and potassium phosphate monobasic solutions and adjusted to $\mathrm{pH} 7.0$.

\subsection{Characterization Methods}

\subsubsection{Microscopy}

High resolution images of $\mathrm{BP}$ morphology were obtained using a FEI/Quanta FEG 250 scanning electron microscope (SEM, Hillsboro, OR, USA) with an accelerating voltage of $5 \mathrm{kV}$. Cross-sectional images of the interlayer structures were snapped after gently breaking the BP samples.

\subsubsection{Physical}

BP thicknesses were measured using vernier calipers. BP electrical conductivity was measured using a Keithley 2450 SourceMeter with an S-302-4 mounting stand and SP4 four-point probe head. Average values were obtained from 2 conductivity measurements taken on 3 independent samples per BP type.

Surface area and pore size were obtained from nitrogen sorption measurements using a NOVA surface area analyzer (Quantachrome Instruments). BP samples were 
first outgassed at $40^{\circ} \mathrm{C}$ for $15 \mathrm{~h} . \mathrm{N}_{2}$ adsorption/desorption isotherms were obtained at $77 \mathrm{~K}$. Specific surface area and pore sizes were determined from the desorption branch using the Brunauer-Emmett-Teller (BET) and BarrettJoyner-Halenda (BJH) methods, respectively.

Water contact angles were obtained at room temperature after delivering a $5 \mu \mathrm{L}$ droplet of water onto the sample surface using a Dataphysics OCA 35 system. Average values were obtained from at least 5 independent samples.

Surface roughness was investigated by profilometry using a Bruker Contour K 3D Optical Microscope. Root mean square roughness (rms) was estimated from images with a size of $126 \times 94 \mu \mathrm{m}$.

\subsubsection{Spectroscopy}

X-ray photoelectron spectroscopy (XPS) data was obtained using an ESCALAB 250 from Thermo Scientific with a monochromated $\mathrm{Al} \mathrm{K} \alpha$ band $(1486.6 \mathrm{eV})$ as the excitation source. The diameter of the surface spot analyzed was $400 \mu \mathrm{m}$. Survey spectra were recorded from 0 to $1200 \mathrm{eV}$ and referenced to the $\mathrm{sp}^{2}$ carbon energy contribution $(\mathrm{C}=\mathrm{C}) \mathrm{C} 1 \mathrm{~s}$ at $284.4 \mathrm{eV}$.

SEM-Energy dispersive $\mathrm{x}$-ray spectroscopy (EDS) analysis was performed using a Zeiss Ultra 55 microscope at $15 \mathrm{kV}$.

Raman spectra were collected using a WITec alpha300 RA system equipped with a $\mathrm{He} / \mathrm{Ne}$ laser $(\lambda=633 \mathrm{~nm})$ and a Zeiss $50 \times$ objective. The data was normalized to the highest peak intensity.

\subsubsection{Electrochemistry}

Electrochemical studies were performed on an Eco Chemie Autolab PGSTAT 100 potentiostat with Nova 2.0 software. The three-electrode system consisted of a BP or glassy carbon (GCE) electrode as the working electrode, a saturated calomel electrode $\mathrm{SCE}\left(\mathrm{KCl}_{\mathrm{sat}}\right)$ as the reference electrode, and a platinum wire as the auxiliary electrode. All solutions for voltammetric studies were purged with argon or oxygen gas for $15 \mathrm{~min}$ before measurements and a gas flow was maintained on top of the solution during analysis. All experiments were conducted at room temperature. Cyclic voltammograms (CVs) for electrochemical characterization of BP were performed at $20 \mathrm{mV} \mathrm{s}^{-1}$. CVs for enzyme-catalyzed oxygen reduction were recorded with a relatively slow scan rate of $1 \mathrm{mV} \mathrm{s}^{-1}$ to phase out most of the capacitive current contribution. All experiments were performed in a $5 \mathrm{~mL}$ volume of $0.1 \mathrm{molL}^{-1}$ PB ( $\mathrm{pH}$ 7.0) solution. Catalytic onset potentials were determined from the foot of the electrocatalytic wave.

\subsection{Procedures}

\subsubsection{Preparation of Buckypaper Electrodes and Bioelectrodes}

Lab-made BP was fabricated based on a vacuum filtration method developed in our previous work [15]. A $1 \mathrm{mg} \mathrm{mL}^{-1}$ MWCNT dispersion was first prepared in DMF with 30 min sonication using a Bandelin sonorex RK100 ultrasonic bath. $58 \mathrm{~mL}$ of the as-prepared suspension was then filtrated using a diaphragm pump (MZ 2C NT model, Vaccubrand) on a Millipore PTFE filter (JHWP, $0.45 \mu \mathrm{m}$ pore size). The resulting $1-\mathrm{BP}$ was rinsed with water, to facilitate the removal of residual DMF, left under vacuum for $1 \mathrm{~h}$, then left to dry in air overnight. The volume of the suspension was calculated to match the mass density of the commercial buckypaper (60 gsm).

For chemical modification, BP was first cut into individual disk electrodes $(\varnothing=10 \mathrm{~mm}) .150 \mu \mathrm{L}$ of hemin solution in DMF was drop coated onto the smooth side of the BP electrode and left to dry in air. An electrical wire was subsequently attached to the back of the electrode then sealed using carbon paste and silicone paste, respectively.

For preparation of bioelectrodes, $\mathrm{BOx}$ was immobilized by drop-casting $150 \mu \mathrm{L}$ of $5 \mathrm{mg} \mathrm{mL}^{-1} \mathrm{BOx}$ in $\mathrm{PB}$ solution onto the electrode surface and leaving the enzyme to adsorb overnight at $4^{\circ} \mathrm{C}$. The electrodes and bioelectrodes were rinsed in $\mathrm{PB}$ buffer prior to electrochemical testing.

\subsubsection{Calculations of Electroactive Surface Area and Surface Coverage of Electroactive Redox Groups}

The electroactive surface area and diffusion coefficients were estimated from $1 \mathrm{mmolL}^{-1}$ redox probes in $\mathrm{PB}$ solution according to the Randles-Sevcik equation:

$\mathrm{I}_{\mathrm{p}}=\left(2.69 \times 10^{5}\right) \mathrm{n}^{3 / 2} \mathrm{AD}^{1 / 2} \mathrm{C} v^{1 / 2}$

where $I_{p}(A)$ is the peak current, $n$ is the number of electrons transferred in the redox reaction, $\mathrm{A}\left(\mathrm{cm}^{2}\right)$ is the geometric area of the electrode, $\mathrm{C}\left(\mathrm{mol} \mathrm{cm}^{-3}\right)$ is the concentration of the redox species, D $\left(\mathrm{cm}^{2} \mathrm{~s}^{-1}\right)$ is the diffusion coefficient and $v\left(\mathrm{~V} \mathrm{~s}^{-1}\right)$ is the scan rate.

Cyclic voltammetry was first performed using a GCE $(\varnothing=3 \mathrm{~mm})$ at varying scan rates to determine the diffusion coefficient of the redox probes from linear plots of peak current versus the square root of the scan rate. The estimated diffusion coefficients are as follows: $5.67 \times$ $10^{-8} \mathrm{~cm}^{2} \mathrm{~s}^{-1}$ for $\mathrm{Ru}\left(\mathrm{NH}_{3}\right)_{6}{ }^{3+/ 2+}, 4.42 \times 10^{-6} \mathrm{~cm}^{2} \mathrm{~s}^{-1}$ for $\mathrm{Fc}^{+/ 0}$, and $2.03 \times 10^{-6} \mathrm{~cm}^{2} \mathrm{~s}^{-1}$ for $\mathrm{Fe}(\mathrm{CN})_{6}^{3-/ 4-}$.

Cyclic voltammetry was subsequently performed on BP electrodes $(\varnothing=10 \mathrm{~mm})$ at varying scan rates to estimate the electrode area (ECSA) after substituting the estimated diffusion coefficient into Equation 1.

The surface coverage of hemin molecules was calculated by integration of the anodic peaks of CVs recorded at $20 \mathrm{mV} \mathrm{s}^{-1}$, according to Equation 2. 
$\Gamma=\frac{\mathrm{Q}}{\mathrm{nFA}^{*}}$

where $\mathrm{Q}$ is the integrated charge, $\mathrm{F}$ is the Faraday constant, $\mathrm{A}^{*}$ is the geometric area of the $\mathrm{BP}$ electrode, and $\mathrm{n}$ is the number of electrons transferred.

\section{Results and Discussion}

\subsection{Physicochemical Characterization of Commercial and Lab-Made BPs}

\subsubsection{Scanning Electron Microscopy}

Figure 1 shows top-down and cross-sectional SEM images of c-BP and l-BP. The c-BP samples display a random, homogeneous and largely macroporous structure (Figure 1A). The CNTs of the c-BP have large diameters of 75-200 $\mathrm{nm}$. On the other hand, 1-BP has a random but homogeneous mesoporous structure of bundled CNTs (Figure 1B). The CNTs of 1-BP have diameters of 10 $20 \mathrm{~nm}$. Cross-sectional images revealed that c-BP has a looser structure with wider interlayer separations (Figure 1C). A denser and more compact structure is observed for 1-BP (Figure 1D).
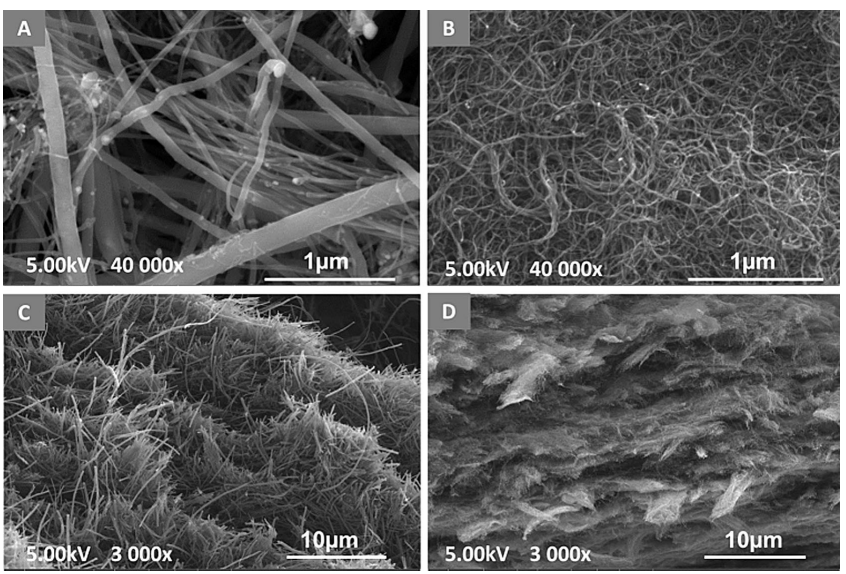

Fig. 1. SEM images showing $(A, B)$ top-down and $(C, D)$ crosssectional views of (left) c-BP and (right) l-BP.

\subsubsection{Film Thickness, Specific Surface Area and Pore Size}

The average BP thicknesses were estimated to be $227 \pm$ $14 \mu \mathrm{m}(n=3)$ and $269 \pm 11 \mu \mathrm{m}(n=5)$ for the commercial and lab-made buckypapers, respectively, which is in the range of other BPs obtained from vacuum filtration $[13,15,23]$. The BET method is widely accepted for calculating the total specific surface area of microporous and mesoporous solids via the adsorption of inert gas molecules [31]. BJH analysis is subsequently employed to evaluate pore size and volume. Both methods have been explored here from nitrogen desorption isotherms for comparison of the two types of buckypapers (Figure S1).
The BET total specific surface area and BJH mesopore size of the BPs are summarized in Table 1. The cBP has a surface area of only $30.2 \mathrm{~m}^{2} \mathrm{~g}^{-1}$. In contrast, 1BP has an estimated surface area of $264 \mathrm{~m}^{2} \mathrm{~g}^{-1}$, which is comparable to previously reported values of $331 \mathrm{~m}^{2} \mathrm{~g}^{-1}$ and $180 \mathrm{~m}^{2} \mathrm{~g}^{-1}$ for BP materials [32,33]. The 1-BP has an almost 9-fold larger surface area than c-BP. This is consistent with the 1-BP having a significantly more mesoporous structure, which is supported by the SEM imaging. The average $\mathrm{BJH}$ pore diameter for both materials (noting that the analysis does not account for macropores) was on the same order of magnitude for both BPs with values of $17.0 \mathrm{~nm}$ and $14.6 \mathrm{~nm}$ for c-BP and l-BP, respectively. The total pore volume, which also accounts for micropores $(<2 \mathrm{~nm})$ and mesopores (2$50 \mathrm{~nm})$, but not macropores $(>50 \mathrm{~nm})$, was negligible for c-BP but significant for l-BP, hence further confirming that c-BPs have a more macroporous structure and that 1-BPs are significantly mesoporous.

Table 1. Surface area and pore size data from $\mathrm{N}_{2}$ sorption isotherms for commercial and lab-made BP.

\begin{tabular}{llll}
\hline Sample & $\begin{array}{l}\text { BET surface } \\
\text { area } / \mathrm{m}^{2} \mathrm{~g}^{-1}\end{array}$ & $\begin{array}{l}\text { BJH mesopores } \\
\text { Pore diameter } / \mathrm{nm}\end{array}$ & Pore volume $/ \mathrm{cm}^{3} \mathrm{~g}^{-1}$ \\
\hline c-BP & 30.2 & 17.0 & $4.3 \times 10^{-4}$ \\
l-BP & 264 & 14.6 & 2.0 \\
\hline
\end{tabular}

\subsubsection{X-Ray Photoelectron Spectroscopy, SEM-Energy Dispersive X-Ray Spectroscopy and Raman Spectroscopy}

The elemental composition, purity and extent of surface defects at the surface of the BPs were characterized by XPS, SEM-EDS and and Raman spectroscopy. XPS analysis revealed an elemental composition of only carbon, nitrogen and oxygen at the BPs. The survey spectra are in Figure S2. The quantitative analysis is summarized in Table 2. The surface of c-BP contains mostly carbon $(95.0 \%)$, considerable oxygen content $(4.4 \%)$ and some residual nitrogen $(0.6 \%)$. The l-BP is also dominated by carbon $(98.8 \%)$ but possesses significantly less oxygen $(1.2 \%)$ and no nitrogen. The survey spectra (Figure S2) for both c-BP and l-BP are largely dominated by the $\mathrm{C} 1 \mathrm{~s}$ envelope at $284.4 \mathrm{eV}$, which corresponds to the expected $\mathrm{sp}^{2}$ structure of the CNTs. Other contributions at $285.3 \mathrm{eV}$ and $289 \mathrm{eV}$ account for hydroxyl and/or $\mathrm{sp}^{3}$ carbons, and carboxylic acid groups, respectively. Unlike the l-BP spectrum, the c-BP spectrum displays a clear contribution at $286.3 \mathrm{eV}$, representing surface carbonyl groups. The absence of metals such as Fe from the XPS spectra, which are typical impurities of CNTs, suggests that the CNTs surface of both BP sources are of high purity [34].

Raman spectroscopy was also performed to characterize the surface structure, and in particular, the extent of defect sites in the buckypapers (Figure 2). Two major 
Table 2. XPS elemental analysis for c-BP and l-BP surfaces.

\begin{tabular}{llll}
\hline Sample & Atomic $\%$ & & N \\
& C & O & ( \\
\hline c-BP & 95.0 & 4.4 & 0.6 \\
l-BP & 98.8 & 1.2 & $/$ \\
\hline
\end{tabular}

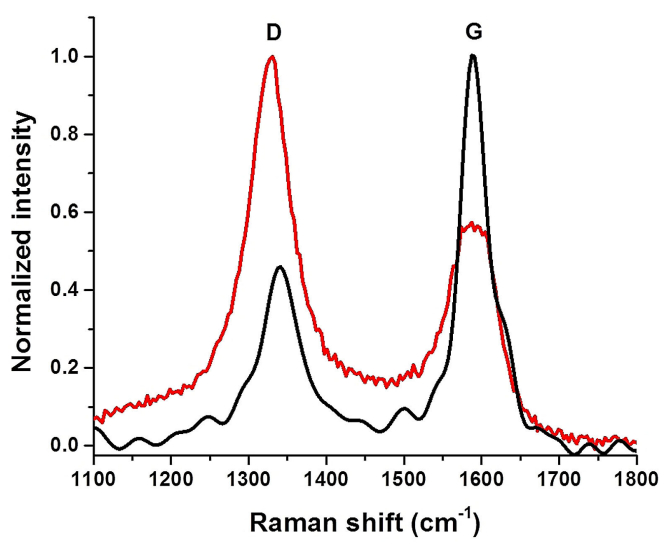

Fig. 2. Raman spectrum of c-BP (black) and 1-BP (red) of the region between 1000 and $2000 \mathrm{~cm}^{-1}$. (A colour version of this figure can be viewed online.)

bands at approximately $1350 \mathrm{~cm}^{-1}$ and $1580 \mathrm{~cm}^{-1}$ are present in the raman spectra, corresponding to the $\mathrm{D}$ band (disordered $\mathrm{sp}^{2}$ carbon) and G-band (crystalline $\mathrm{sp}^{2}$ carbon), respectively. The ratio of the $\mathrm{D}$ and $\mathrm{G}$ band intensities was used to provide a relative but not quantitative comparison of the two BP samples. The c-BP has a comparably more ordered and higher structural purity/crystallinity structure $\left(\mathrm{I}_{\mathrm{D}} / \mathrm{I}_{\mathrm{G}}=0.52\right)$ while l-BP has a more apparent defective surface $\left(\mathrm{I}_{\mathrm{D}} / \mathrm{I}_{\mathrm{G}}=1.74\right)$.

\subsubsection{Contact Angle, Surface Profilometry and Electrical Conductivity}

Water contact angle (CA) measurements were performed on c-BP and 1-BP. Similar values of $134 \pm 8^{\circ}$ and $127 \pm 18^{\circ}$ were obtained for c-BP and l-BP, respectively, which is consistent with both surfaces being hydrophobic $\left(>90^{\circ}\right)$. It was considered that the c-BP, with its high surface oxygen content, might be more hydrophilic than l-BP, but this was not the case. The surface roughness and heterogeneity, rather than the chemical modification, therefore appears to have a more influential effect on the wetting behaviour of BP.

Surface profilometry imaging over large areas of $c a$. $100 \mu \mathrm{m}^{2}$ revealed further insight into the surface structure of the BPs. A larger average roughness value of $4.8 \mu \mathrm{m}$ rms was estimated for c-BP compared to a value of $1.9 \mu \mathrm{m}$ rms for l-BP. The profilometry clearly shows that the c-BP has greater surface roughness, which helps to explain its hydrophobicity despite the higher surface oxygen content [35].
The average electrical conductivities of c-BP and l-BP are $22 \pm 3 \mathrm{Scm}^{-1}$ and $13 \pm 1 \mathrm{Scm}^{-1}$ respectively. These results are similar to conductivity values of around 20 $30 \mathrm{Scm}^{-1}$ reported for randomly ordered BP [23,36,37]. The lower electrical conductivity for 1-BP, despite the more compact and inter-connected structure, can be attributed to the increase of $\mathrm{sp}^{3}$-type carbon (e.g. higher defect/lower crystallinity) carbon structure inferred from the Raman spectra.

\subsection{Electrochemical Characterization of Commercial and Lab-Made BPs}

Figure 3 shows the background voltammetric response recorded at the two $\mathrm{BP}$ electrodes in $0.1 \mathrm{molL}^{-1} \mathrm{~PB}$ at $20 \mathrm{mV} \mathrm{s}^{-1}$. The two electrodes were scanned between $-0.9 \mathrm{~V}$ and $1.0 \mathrm{~V}$ vs. SCE, which is a relevant potential window to observe the electrochemical stability of carbon electrodes in aqueous solution [38]. The c-BP electrode unexpectedly exhibits a pair of redox peaks at $\mathrm{E}_{\mathrm{pc}}=$ $-0.2 \mathrm{~V}$ and $\mathrm{E}_{\mathrm{pa}}=0.5 \mathrm{~V}$. In contrast, the 1-BP electrodes exhibited a steady non-faradaic current response over the same potential range. The redox peaks at c-BP are attributed to electroactive surface-bound oxygen functionalities such as polyaromatic carbonyl, nitroso and phenol groups. The possibility that the redox peaks are due to metal oxides is not entirely ruled out on the basis that $\mathrm{Fe}$ impurities were observed by SEM-EDS (Figure S3). The c-BP electrode showed a 10-fold larger background capacitive current. The larger capacitance observed at c$\mathrm{BP}$ (Figure 1C) is attributed to the looser packing density of CNT bundles, increased surface roughness and the higher concentration of oxygen functionalities. Next we evaluated the electron transfer reactivity of c-BP and l-BP electrodes with four different redox probes. The mid-point potential $\left(\mathrm{E}_{\mathrm{m}}\right)$, peak-to-peak potential separation $\left(\Delta \mathrm{E}_{\mathrm{P}}\right)$, electroactive surface area (ECSA) and heterogeneous rate constant $\left(\mathrm{k}^{\circ}\right)$ of the $\mathrm{BP}$ electrodes are summarized in Table S1. The heterogeneous electron transfer rate constant was calculated based on the Nicholson method [39]. The electron transfer kinetics at carbon electrodes depend on the electronic and surface structure of the electrode

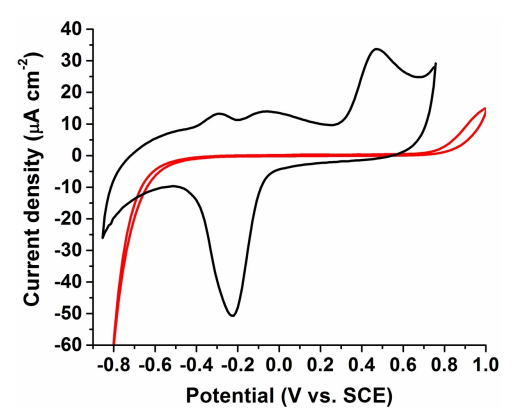

Fig. 3. Representative cyclic voltammograms recorded at (black) c-BP and (red) l-BP electrodes in $0.1 \mathrm{~mol} \mathrm{~L}^{-1} \mathrm{~PB}(\mathrm{pH} 7.0)$ solution at $20 \mathrm{mV} \mathrm{s}^{-1}$. (A colour version of this figure can be viewed online.) 
and the nature of the redox probe used $[38,40]$, hence we explored several different redox probes. Initially, experiments were performed with $\mathrm{Ru}\left(\mathrm{NH}_{3}\right)_{6}{ }^{3+12+}$ and $\mathrm{FcMeOH}^{+/ 0}$, which are outer-sphere redox probes that are relatively "insensitive" to electrode surface chemistry. $\mathrm{CVs}$ recorded at BP electrodes revealed well-defined and chemically reversible redox couples for the ruthenium and ferrocene probes at c-BP and 1-BP (Figure 4A and Figure $4 B$ ). Similar mid-point potential and peak potential separation values to those obtained at GCE are observed (Table S1).
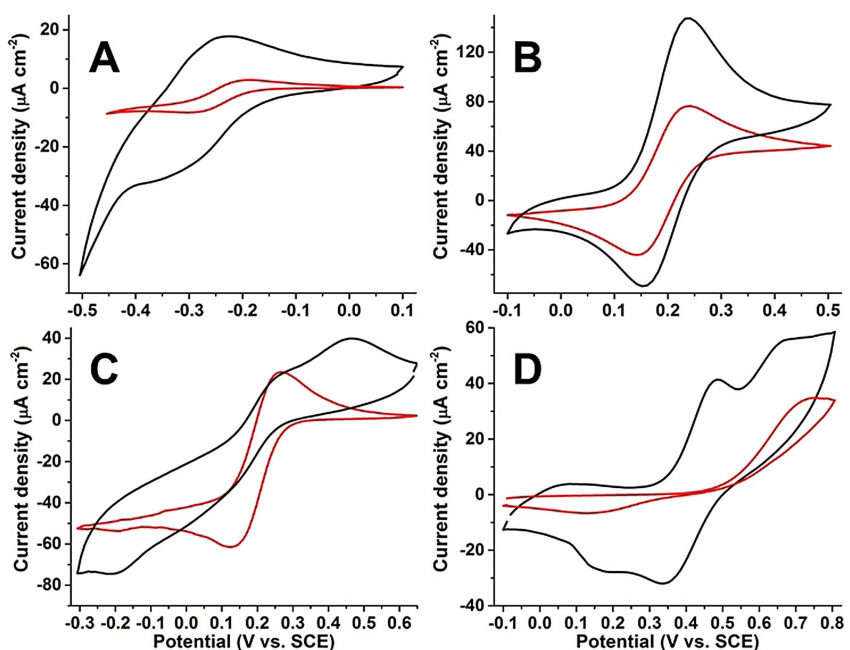

Fig. 4. Representative cyclic voltammograms recorded at c-BP (black) and l-BP (red) electrodes in $1 \mathrm{mmol} \mathrm{L}^{-1}$ redox probe solutions: (A) $\mathrm{Ru}\left(\mathrm{NH}_{3}\right)_{6}{ }^{3+12+}$, (B) $\mathrm{FcMeOH}^{+/ 0}$, (C) $\mathrm{Fe}(\mathrm{CN})_{6}^{3-/ 4-}$ in $0.1 \mathrm{molL}^{-1} \mathrm{~PB} \mathrm{pH} \mathrm{7.0,} \mathrm{and} \mathrm{(D)} \mathrm{Fe}^{3+/ 2+}$ in $0.5 \mathrm{molL}^{-1} \mathrm{H}_{2} \mathrm{SO}_{4}$. Scan rate: $20 \mathrm{mVs}^{-1}$. (A colour version of this figure can be viewed online.)

A less well-defined cathodic peak was observed for $\mathrm{Ru}\left(\mathrm{NH}_{3}\right)_{6}{ }^{3+12+}$ at $\mathrm{c}-\mathrm{BP}$, which suffers from interference due to the reduction of surface oxygen and the presence of the adsorbed complex. Both the ruthenium and ferrocene redox probes were used to estimate the electroactive surface area (ECSA) of lab-made and commercial buckypapers. ECSA values of $c a .0 .5 \pm 0.3 \mathrm{~cm}^{2}$ were observed for both probes at l-BP. In contrast, c-BP showed much larger ECSA values of $1.5 \pm 0.1$ and $5.4 \pm 2.1 \mathrm{~cm}^{2}$ for $\mathrm{FcMeOH}^{+/ 0}$ and $\mathrm{Ru}\left(\mathrm{NH}_{3}\right)_{6}{ }^{3+/ 2+}$, respectively. The ECSA data therefore suggests that c-BP has a larger surface area which is contrary to the total specific surface area values calculated by gas adsorption, and the SEM images. The smaller ECSA values observed at l-BP suggest that the structure is less permeable to positive and neutral redox species in aqueous solution. As a result, the total volume of the pores in the 1-BP structure is not effectively contacted by the redox probe solutions. In contrast, the more loosely packed structure of c-BP (Figure 1) better facilitates the diffusion of the redox probes into the bulk structure. The CVs obtained at c-BP, but not l-BP, also show evidence for the weak adsorption of both the ferrocene and ruthenium species. The adsorbed electroactive species contribute to the peak current and therefore, to some extent, result in an overestimation of the ECSA values at c-BP. The ECSA value at c-BP was 3.5fold larger using the larger $\mathrm{Ru}\left(\mathrm{NH}_{3}\right)_{6}{ }^{3+12+}$ probe which reflects that this complex adsorbs to a greater extent at c$\mathrm{BP}$ compared to $\mathrm{FcMeOH}$. The adsorption of positively charged $\mathrm{Ru}\left(\mathrm{NH}_{3}\right)_{6}{ }^{3+12+}$ and $\mathrm{FcMeOH}^{+}$at c-BP can occur via electrostatic interactions between surface bound oxygen residues, which would be negatively charged at neutral $\mathrm{pH}$, and the positively charged oxidised species. The possibility that the reduced neutral form of $\mathrm{FcMeOH}$ adsorbs at the oxidised graphitic surface is not ruled out [41].

Electron transfer rates at the buckypapers were estimated based on the $\mathrm{FcMeOH}^{+/ 0}$ probe and revealed slower heterogeneous electron transfer at c-BP compared to $1-\mathrm{BP}$, which is attributed to differences in the physical and electronic structure of the CNTs. For example, Banks et al. have shown that catalytic electron transfer on CNTs relies on edge-plane sites and tube ends [42]. It is possible that 1-BP, which has shorter and smaller diameter CNT bundles with a more defective structure, benefit from having more exposed edge-plane like sites.

$\mathrm{Fe}(\mathrm{CN})_{6}{ }^{3-/ 4-}$ is a well-known surface-sensitive redox probe. At c-BP, the redox peaks for this probe are poorly defined. In addition to the weak signal, we observe the redox activity of the oxide groups at $-0.2 \mathrm{~V}$ and $0.5 \mathrm{~V}$. The ferricyanide redox couple was unfortunately not sufficiently resolved at c-BP to obtain kinetic or surface area data. A well-defined electrochemical response, similar to that observed at GCE, was observed at 1-BP. Faster electron transfer by more than 2-fold was observed at 1$\mathrm{BP}$ compared to GCE, highlighting the benefits of l-BP as an advanced type of carbon electrode. Both GCE and 1BP exhibited slower electron transfer kinetics towards $\mathrm{Fe}(\mathrm{CN})_{6}{ }^{3-14-}$ compared to $\mathrm{Ru}\left(\mathrm{NH}_{3}\right)_{6}{ }^{3+/ 2+}$, which is typical for carbon electrodes [38]. The estimated ECSA value for 1-BP of $0.56 \mathrm{~cm}^{2}$ using $\mathrm{Fe}(\mathrm{CN})_{6}{ }^{3-14-}$ is very similar to the ca. $0.5 \mathrm{~cm}^{2}$ areas estimated using the ferrocene and ruthenium probes at l-BP. The similar ECSA values for all three probes suggests that 1-BP is less sensitive to charged species and adsorption effects compared to c-BP.

To further assess the presence and activity of oxygen species on the CNT surface of c-BP, a more specific surface-sensitive redox probe was also investigated. The $\mathrm{Fe}^{3+12+}$ redox probe was chosen as it is known to be highly sensitive to surface oxide [37]. CVs recorded at the oxygen-rich c-BP showed a reversible couple of the probe with a small peak separation of $126 \mathrm{mV}$, consistent with "fast" apparent electron transfer kinetics. Additional redox peaks were also present, which appear to be due to the presence of the surface oxide groups which promote a positive shift in potential. In contrast, a much larger peak separation of $413 \mathrm{mV}$ was observed at l-BP, highlighting slower electron transfer behaviour at l-BP compared to c-BP. The exact nature of the complex 

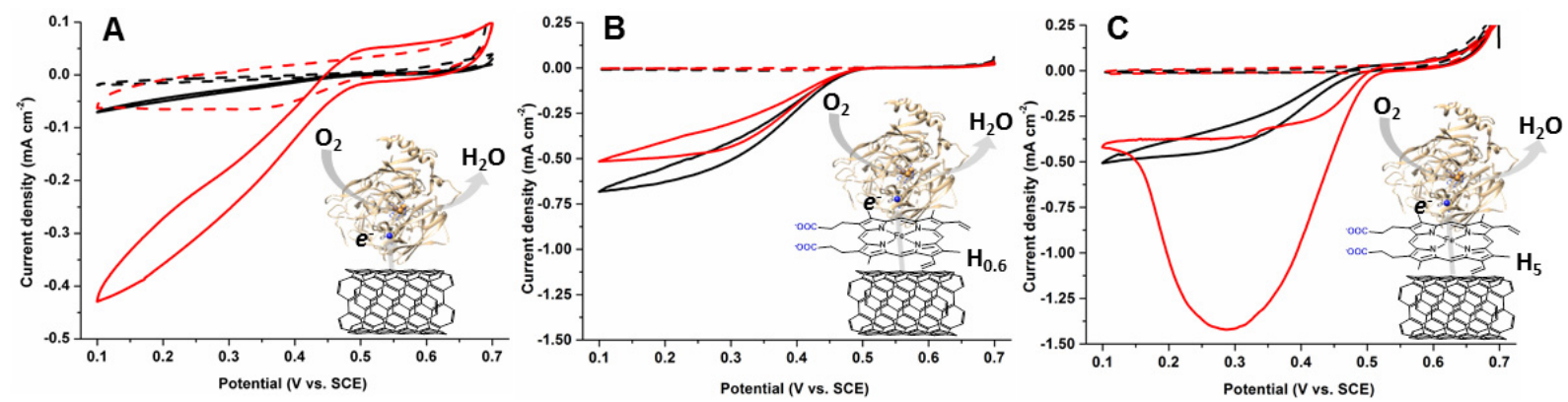

Fig. 5. Representative cyclic voltammograms for (A) unmodified, (B) $\mathrm{H}_{0.6}$ and (C) $\mathrm{H}_{5}$ modified c-BPs (black) and l-BPs (red) with adsorbed $\mathrm{BOx}$ at the electrode surfaces in quiescent Ar-saturated (dashes) or $\mathrm{O}_{2}$-saturated (lines) in $\mathrm{pH} 7.0 \mathrm{~PB}$ buffer $\left(1 \mathrm{mV} \mathrm{s}^{-1}, 1^{\text {st }}\right.$ scan displayed). (A colour version of this figure can be viewed online.)

redox behaviour is not clear. Nevertheless, the data obtained using the $\mathrm{Fe}^{3+/ 2+}$ probe, which reveals a strong interaction of the iron complex with c-BP but not l-BP, provides supporting evidence for the presence of surface oxygen groups.

\subsection{Bioelectrocatalytic Activity of Enzyme-Modified Commercial and Lab-Made BPs}

The buckypapers were investigated for the construction of enzymatic bioelectrodes for bioelectrocatalysis. In this study we chose to explore the bioelectrocatalytic reduction of $\mathrm{O}_{2}$ to water, which is currently the most important reaction for cathodes in enzymatic biofuel cell research. The oxygen reduction reaction (ORR) is investigated here, using adsorbed $\mathrm{BOx}$ as the biocatalyst, and relies on direct electron transfer between the electrode and the trinuclear $\mathrm{Cu}$ centre of the immobilised enzymes.

Figure 5A shows $\mathrm{CVs}$ recorded for bioelectrocatalytic $\mathrm{O}_{2}$ reduction at $\mathrm{BOx}$ modified l-BP and c-BP electrodes. Under $\mathrm{O}_{2}$-saturated conditions, both BPs displayed onset potentials of $0.51 \pm 0.01 \mathrm{~V}$. For c-BP, the catalytic current $\left(I_{\text {cat }}\right)$ is negligible $\left(-23 \pm 15 \mu \mathrm{A} \mathrm{cm}^{-2}\right)$. For 1-BP, the catalytic current density was 9-fold larger, reaching $-214 \pm 74 \mu \mathrm{A} \mathrm{cm}^{-2}$ at $0.3 \mathrm{~V}$. This current density is similar to our previous results obtained at unmodified BP with adsorbed BOx $\left(-225 \pm 91 \mu \mathrm{A} \mathrm{cm}^{-2}\right)$ under equivalent conditions [15]. The improvement in DET-type bioelectrocatalysis for unmodified l-BP compared to unmodified c-BP was expected as 1-BP has a significantly higher total specific BET surface area and a more defective CNT structure (e.g. more reactive vacancies). Enhancements in DET at BOx modified CNT electrodes are also strongly related to the presence of negatively-charged surface groups which orientate the enzyme via arginine residues near the $\mathrm{T} 1 \mathrm{Cu}$ centre [43-45]. It was therefore postulated that the oxygen-rich c-BP, with negatively-charged surface groups at $\mathrm{pH} \mathrm{7,} \mathrm{would} \mathrm{promote} \mathrm{a} \mathrm{stronger} \mathrm{DET} \mathrm{response}$ compared to l-BP. This is however not the case. The surface charge and the presence of oxygen groups are therefore relatively insignificant factors for DET bioelectrocatalysis at buckypaper. Hence, the overall negative charge of the $\mathrm{BOx}$ at $\mathrm{pH} 7.0$ (isoelectric point $(\mathrm{pI})=4.1$ ) is apparently not a crucial factor for its orientation. On the contrary, a large specific surface area and the type and structure of the CNTs in the buckypaper (e.g. the pi-pi network and CNT dimensions $[5,43,46,47])$ are expected to play a greater role in favouring $\mathrm{BOx}$ immobilization. For example, concerning the type of CNTs used, Mugurama et al. elegantly reported the importance of the size of CNTs for achieving DET-type bioelectrocatalysis [46]. Next we considered the role of CNT size on the DET bioelectrocatalysis with immobilised $\mathrm{BOx}$. Based on the average outer diameter of the CNTs of c-BP, estimated from SEM images, we estimate that the nanotubes of $\mathrm{c}$ $\mathrm{BP}$ represent a more flat surface upon interaction with the enzyme (assuming the tube as a disk near the pocket). Figure S4 shows a 3D structural view of the enzyme and highlights the hydrophilic substrate pocket, estimated to be $1.5 \mathrm{~nm}$ wide, where the active site is located. On this basis, only $0.0001 \%$ of the surface area of the disk of an average CNT in c-BP (ca. $137 \mathrm{~nm}$ diameter) would penetrate the pocket for a more intimate interaction with the $\mathrm{T} 1 \mathrm{Cu}$ centre. In contrast, the average nanotubes of $\mathrm{l}$ BP ( $c a .15 \mathrm{~nm}$ diameter) can better penetrate the substrate pocket such that $0.030 \%$ of the surface area of the CNTs disk could enter the enzyme pocket (more details concerning this calculation are given in the SI file).

With the aim to increase the favourable adsorption and orientation of BOx on the electrode, the two different buckypapers were modified with hemin, an iron-protoporphyrin with a substrate-like structure, via pi-pi stacking interactions [15,44]. Hemin-modified BP electrodes (c$\mathrm{BP}-\mathrm{H}$ and $\mathrm{l}-\mathrm{BP}-\mathrm{H})$ were prepared by drop-casting 0.6, 5 or $10 \mathrm{mmol} \mathrm{L}^{-1}$ hemin solutions prepared in DMF. Data from cyclic voltammetry studies performed in $\mathrm{PB}$ are summarized in Table S2. The presence of the $\mathrm{Fe}^{2+/ 3+}$ redox signal at $\mathrm{E}_{1 / 2}=-0.330 \pm 0.045 \mathrm{~V}$ was utilized to evaluate the surface coverage of electroactive porphyrin groups after pi-pi stacking immobilisation on the CNT network of the BP. Increasing the hemin concentration of the modifier solution resulted in an increase in the porphyrin surface coverage for the buckypaper electrodes for the three concentrations investigated at both l-BP and 
c-BP. As a result, unambiguous enhancements were observed in the bioelectrocatalytic currents recorded in the presence of $\mathrm{O}_{2}$ saturated $\mathrm{PB}$ for the hemin-modified BP electrodes. As shown in Figure 5B, the c-BP- $\mathrm{H}_{0.6}$ and 1$\mathrm{BP}^{-\mathrm{H}_{0.6}}$ electrodes displayed onset potentials of $c a .0 .53 \mathrm{~V}$ compared to $c a .0 .51 \mathrm{~V}$ at the unmodified electrodes (Figure 5A). The improved onset potentials and more pronounced ORR slope at hemin modified BP is consistent with more efficient direct electron transfer and an improved thermodynamic driving force between the CNTs and the redox site of the enzyme. More specifically, it results from an improved orientation of the T1 redox centre oriented towards the CNT walls due to the carboxylic groups of the porphyrin and its pi-pi conjugated system $[43,44,48]$.

At c-BP-H, the catalytic current densities measured at $0.3 \mathrm{~V}$ during the forward scan in $\mathrm{O}_{2}$-saturated $\mathrm{PB}$ were $-506 \pm 11 \mu \mathrm{A} \mathrm{cm}^{-2}, \quad-296 \pm 145 \mu \mathrm{Acm}^{-2}$ and $-142 \pm$ $71 \mu \mathrm{A} \mathrm{cm}^{-2}$, for electrodes modified from 0.6, 5 and $10 \mathrm{mmol} \mathrm{L}^{-1}$ hemin modifier solutions, respectively. This result shows that the use of modifier concentrations beyond $0.6 \mathrm{mmolL}^{-1}$, or surface coverages $\geq 1.7 \pm 0.2 \times$ $10^{-8} \mathrm{~mol} \mathrm{~cm}^{-2}$, does not improve the adsorption and orientation of $\mathrm{BOx}$ at c-BP. In fact, c-BP-H electrodes prepared with 10 - to 20 -fold higher surface coverages of hemin had a negative impact on DET bioelectrocatalysis. We consider that the loss in catalytic current is due to the desorption and/or de-orientation of the enzyme.

At l-BP-H, the catalytic current densities drastically increased with increasing modifier concentration from $0.6 \mathrm{mmol} \mathrm{L}^{-1}$ to $5 \mathrm{mmol} \mathrm{L}^{-1}$ then remained constant after use of $10 \mathrm{mmol} \mathrm{L}^{-1}$ modifier solution. The highest catalytic current density reached was $-1336 \pm 191 \mu \mathrm{Acm}^{-2}$ at $0.3 \mathrm{~V}$ in $\mathrm{O}_{2}$-saturated $\mathrm{PB}$ solution when the surface coverage of porphyrin groups was $31.8 \pm 18.6 \times 10^{-8} \mathrm{~mol} \mathrm{~cm}^{-2}$ (Figure $5 \mathrm{C}$ ). As was observed for c-BP, the modification of 1 BP with hemin groups clearly improved the electrocatalytic efficiency of the oxygen reduction reaction. The results obtained for c-BP-H and l-BP-H highlight limitations for the commercial buckypaper (Table S3). Under the best conditions, the catalytic current at c-BP-H was more than two-fold smaller than that observed at l-BP-H. Furthermore, the use of high surface coverages of hemin beyond $1.7 \pm 0.2 \times 10^{-8} \mathrm{~mol} \mathrm{~cm}^{-2}$ enhanced DET bioelectrocatalysis at lab-made buckypaper whereas detrimental effects on catalysis were observed at commercial buckypaper. We consider that the different physical structures of the BP samples (e.g. porosity and CNT size) are largely responsible. For example, the $\mathrm{BJH}$ pore volume is significantly larger for 1-BP compared to c-BP (see Table 1), and therefore, 1-BP benefits from significantly more mesopores which can accommodate higher loadings of BOx. Sugimoto et al. have highlighted the importance of mesoporous structures for enhancing DET in a recent paper using Ketjen black electrodes [5]. The beneficial enzyme penetration effect due to the smaller CNTs of labmade buckypaper is also considered to be an important factor after modification of the surface with porphyrin molecules.

Another key difference in the electrocatalytic behaviour between the lab-made and commercial buckypaper electrodes is that, at the best performing $1-\mathrm{BP}-\mathrm{H}_{5}$ electrode, a large catalytic reduction peak was observed at $0.3 \mathrm{~V}$ which reached a pseudo "steady-state" at $0.1 \mathrm{~V}$ $\left(\mathrm{I}_{\text {cat }}=-0.420 \mathrm{~mA} \mathrm{~cm}^{-2}\right)$ (Figure 5). It is noted that similar behaviour was also observed at $1-\mathrm{BP}-\mathrm{H}_{10}$ electrode (Figure S5). This is in sharp contrast to the "resistive slope" observed at unmodified BP (reflecting random enzyme orientation, Figure 5A) and the well-defined steady statetype voltammograms observed at c-BP-H electrodes. The catalytic peak behaviour was only observed during the forward scan and is attributed to a mass transport limitation of dissolved $\mathrm{O}_{2}$ through the compact 3D mesoporous architecture of the electrode. On the reverse scan, no peak is observed as less oxygen is available in the bulk structure. It is also evident that the slope of the catalytic reduction wave at 1-BP- $\mathrm{H}_{5}$ (Figure 5C) and l-BP$\mathrm{H}_{10}$ (Figure S5) is significantly steeper compared to the responses observed at the hemin-modified c-BP electrodes, consistent with a more rapid rate of oxygen reduction owing not only to the presence of high coverages of hemin but also higher loadings of oriented BOx.

Experiments performed in the absence of oxygen with the hemin-modified BP electrodes with immobilised BOx revealed the possibility to directly observe the $\mathrm{T} 1 \mathrm{Cu}$ redox couple of the enzyme, but only at the l-BP electrode (Figure S6). In fact, the redox couple of the $\mathrm{Cu}$ site was only observed for electrodes prepared with high surface coverages of $>1.32 \times 10^{-7} \mathrm{~mol} \mathrm{~cm}^{-2}$. This direct redox response of the enzyme was not observed at c-BP electrodes prepared with similarly high surface coverages and hence the superior electrical connection of the enzyme is attributed specifically to the unique mesoporous structure and the size of the CNTs present in the 1-BP electrode.

From the oxidation peak of the T1 site (see Figure S6), the average surface coverage of enzyme on l-BP- $\mathrm{H}_{5}$ and lBP- $\mathrm{H}_{10}$ was estimated to be $2.73 \times 10^{-10} \mathrm{~mol} \mathrm{~cm}^{-2}$, which is a significantly higher enzyme loading compared to that previously reported at CNT modified GC electrodes with immobilised BOx $\left(5.0 \times 10^{-12} \mathrm{~mol} \mathrm{~cm}^{-2}\right)$ [44].

\section{Conclusion}

In this study, we have compared the physico-chemical and catalytic behaviour of commercial and lab-made buckypapers. Very different physico-chemical properties were reported and these were found to greatly influence the bioelectrocatalytic performance. Commercial BP possesses a higher oxygen content but more ordered and looser structure with significantly wider diameter nanotubes compared to our lab-made BP. Electrochemical characterisation experiments revealed complexity for the commercial BP owing to the presence of electroactive oxygen groups which also promoted adsorption of positively-charged redox species and suffered from a short 
potential window for a carbon electrode. The electrochemical potential window for $1-\mathrm{BP}$ was $1.6 \mathrm{~V}$ and the redox probe behaviour was very classical to quasireversible systems compared to other carbon electrodes. The electroactive surface area data contradicted the BET surface area measurements. The lower than expected electroactive surface area at 1-BP suggests that the charged redox species did not effectively diffuse into the denser mesoporous structure of 1-BP during the time scale of the experiment. Additionally, the electroactive surface area of c-BP is likely overestimated due to adsorption effects via the negatively-charged surface oxygen at $\mathrm{pH} 7$.

BP electrodes modified with BOx were studied and the best catalytic performance at unmodified and heminmodified electrodes was obtained at l-BP. At unmodified $\mathrm{BP}$, negligible DET was observed at commercial BP compared to the lab-made counterpart. This suggests that the negatively charged oxygen groups did not promote DET catalysis and that the structure of c-BP was less well suited to effective enzyme adsorption and orientation. At hemin-modified CNT electrodes functionalized with DET promoting porphyrin groups, enhanced currents were observed. The DET enhancement at 1-BP was superior and gave a current density of $-1.32 \mathrm{~mA} \mathrm{~cm}^{-2}$ and a very pronounced slope for the bioelectrocatalytic wave. Furthermore, the $\mathrm{T} 1 \mathrm{Cu}$ centre was only observed using the 1$\mathrm{BP}$, and only for high surface loadings of porphyrin. The data shows that a highly mesoporous surface but also a high coverage of hemin are required for effective DETtype bioelectrocatalysis with $\mathrm{BOx}$ at l-BP. This is in contrast to c-BP which requires comparatively lower hemin coverage to obtain optimal catalytic current outputs. This appears to be related to the 9-times smaller BET surface area and likely similar reduction in the enzyme loading. All in all, this report gives the baseline for electrochemical properties of two prominent types of BP and demonstrates that several inter-dependant physico-chemical "features" play a large role in the efficiency and complexity of bioelectrocatalytic systems.

\section{Acknowledgements}

This work was supported by Labex Arcane (ANR-11LABX-0003-01), ANR-15-JTIC-0002-01, Nanobio Chimie ICMG FR 2607. Xiaohong Chen is grateful for a Université Grenoble Alpes PhD scholarship. Dr. Jean-Luc Putaux is acknowledged for SEM imaging, respectively. The authors are grateful to Valérie Flaud from ICGM Montpelier XPS characterisation. We would like to thank Francine Roussel (Grenoble Institute of Technology) for the SEM-EDS analysis. The authors would like to acknowledge Hughes Bonnet and Emmanuel Paris from Brucker France for profilometry imaging.

\section{References}

[1] A. Trifonov, K. Herkendell, R. Tel-Vered, O. Yehezkeli, M. Woerner, I. Willner, ACS Nano 2013, 7, 11358-11368.

[2] S. Tsujimura, K. Murata, W. Akatsuka, J. Am. Chem. Soc. 2014, 136, 14432-14437.

[3] S. Cosnier, A. J. Gross, A. Le Goff, M. Holzinger, J. Power Sources 2016, 325, 252-263.

[4] S. D. Minteer, P. Atanassov, H. R. Luckarift, G. R. Johnson, Mater. Today 2012, 15, 166-173.

[5] Y. Sugimoto, Y. Kitazumi, O. Shirai, K. Kano, Electrochemistry 2017, 85, 82-87.

[6] S. Cosnier, M. Holzinger, A. Le Goff, Front. Bioeng. Biotechnol. 2014, 2, 45.

[7] H.-Q. Xia, Y. Kitazumi, O. Shirai, H. Ozawa, M. Onizuka, T. Komukai, K. Kano, Bioelectrochemistry 2017, 118, 70-74.

[8] N. Lalaoui, M. Holzinger, A. Le Goff, S. Cosnier, Chem. Eur. J. 2016, 22, 10494-10500.

[9] M. T. Meredith, M. Minson, D. Hickey, K. Artyushkova, D. T. Glatzhofer, S. D. Minteer, ACS Catal. 2011, 1, 16831690.

[10] M. Jönsson-Niedziolka, A. Kaminska, M. Opallo, Electrochim. Acta 2010, 55, 8744-8750.

[11] F. Giroud, K. Sawada, M. Taya, S. Cosnier, Biosens. Bioelectron. 2017, 87, 957-963.

[12] A. J. Gross, M. P. Robin, Y. Nedellec, R. K. O'Reilly, D. Shan, S. Cosnier, Carbon 2016, 107, 542-547.

[13] M. Bourourou, K. Elouarzaki, M. Holzinger, C. Agnes, A. Le Goff, N. Reverdy-Bruas, D. Chaussy, M. Party, A. Maaref, S. Cosnier, Chem. Sci. 2014, 5, 2885-2888.

[14] V. Scherbahn, M. T. Putze, B. Dietzel, T. Heinlein, J. J. Schneider, F. Lisdat, Biosens. Bioelectron. 2014, 61, 631-638.

[15] A. J. Gross, X. Chen, F. Giroud, C. Abreu, A. Le Goff, M. Holzinger, S. Cosnier, ACS Catal. 2017, 7, 4408-4416.

[16] K. MacVittie, J. Halámek, L. Halámková, M. Southcott, W. D. Jemison, R. Lobel, E. Katz, Energy Environ. Sci. 2013, 6, 81-86.

[17] C. Hou, A. Liu, Electrochim. Acta 2017, 245, 303-308.

[18] L. Halámková, J. Halámek, V. Bocharova, A. Szczupak, L. Alfonta, E. Katz, J. Am. Chem. Soc. 2012, 134, 5040-5043.

[19] R. C. Reid, S. D. Minteer, B. K. Gale, Biosens. Bioelectron. 2015, 68, 142-148.

[20] A. Szczupak, J. Halámek, L. Halámková, V. Bocharova, L. Alfonta, E. Katz, Energy Environ. Sci. 2012, 5, 8891-8895.

[21] E. Katz, K. MacVittie, Energy Environ. Sci. 2013, 6, 27912803.

[22] A. G. Rinzler, J. Liu, H. Dai, P. Nikolaev, C. B. Huffman, F. J. Rodríguez-Macías, P. J. Boul, A. H. Lu, D. Heymann, D. T. Colbert, Appl. Phys. A 1998, 67, 29-37.

[23] L. Hussein, G. Urban, M. Krueger, Phys. Chem. Chem. Phys. 2011, 13, 5831-5839.

[24] C. W. N. Villarrubia, K. Artyushkova, S. O. Garcia, P. Atanassov, J. Electrochem. Soc. 2014, 161, H3020-H3028.

[25] C. Stines-Chaumeil, E. Roussarie, N. Mano, Biochim. Open 2017, 4, 36-40.

[26] J. A. Cracknell, T. P. McNamara, E. D. Lowe, C. F. Blanford, Dalton Trans. 2011, 40, 6668-6675.

[27] L. Hussein, Y. J. Feng, N. Aonso-Vante, G. Urban, M. Krueger, Electrochim. Acta 2011, 56, 7659-7665.

[28] G. P. M. K. Ciniciato, C. Lau, A. Cochrane, S. S. Sibbett, E. R. Gonzalez, P. Atanassov, Electrochim. Acta 2012, 82, 208-213.

[29] D. V. Pankratov, Y. S. Zeifman, O. V. Morozova, G. P. Shumakovich, I. S. Vasil'eva, S. Shleev, V. O. Popov, A. I. Yaropolov, Electroanalysis 2013, 25, 1143-1149. 
[30] A. J. Gross, X. Chen, F. Giroud, C. Travelet, R. Borsali, S. Cosnier, J. Am. Chem. Soc. 2017, 139, 16076-16079.

[31] K. Sing, Colloids Surf. Physicochem. Eng. Asp. 2001, 187$188,3-9$.

[32] A. G. Gonçalves, J. L. Figueiredo, J. J. M. Órfão, M. F. R. Pereira, Carbon 2010, 48, 4369-4381.

[33] A. Zebda, C. Gondran, A. L. Goff, M. Holzinger, P. Cinquin, S. Cosnier, Nat. Commun. 2011, 2, 370.

[34] E. R. Edwards, E. F. Antunes, E. C. Botelho, M. R. Baldan, E. J. Corat, Appl. Surf. Sci. 2011, 258, 641-648.

[35] R. N. Wenzel, J. Phys. Colloid Chem. 1949, 53, 1466-1467.

[36] J. Zhang, D. Jiang, H.-X. Peng, F. Qin, Carbon 2013, 63, 125132.

[37] L. Hussein, S. Rubenwolf, F. von Stetten, G. Urban, R. Zengerle, M. Krueger, S. Kerzenmacher, Biosens. Bioelectron. 2011, 26, 4133-4138.

[38] R. L. McCreery, Chem. Rev. 2008, 108, 2646-2687.

[39] R. S. Nicholson, Anal. Chem. 1965, 37, 1351-1355.

[40] P. Chen, R. L. McCreery, Anal. Chem. 1996, 68, 3958-3965.

[41] A. S. Cuharuc, G. Zhang, P. R. Unwin, Phys. Chem. Chem. Phys. 2016, 18, 4966-4977.
[42] C. E. Banks, T. J. Davies, G. G. Wildgoose, R. G. Compton, Chem. Commun. 2005, 829-841.

[43] H. Xia, Y. Kitazumi, O. Shirai, K. Kano, J. Electroanal. Chem. 2016, 763, 104-109.

[44] N. Lalaoui, A. Le Goff, M. Holzinger, S. Cosnier, Chem. Eur. J. 2015, 21, 16868-16873.

[45] I. Mazurenko, K. Monsalve, J. Rouhana, P. Parent, C. Laffon, A. L. Goff, S. Szunerits, R. Boukherroub, M.-T. GiudiciOrticoni, N. Mano, ACS Appl. Mater. Interfaces 2016, 8, 23074-23085.

[46] H. Muguruma, H. Iwasa, H. Hidaka, A. Hiratsuka, H. Uzawa, ACS Catal. 2017, 7, 725-734.

[47] K. So, M. Onizuka, T. Komukai, Y. Kitazumi, O. Shirai, K. Kano, Electrochim. Acta 2016, 192, 133-138.

[48] K. So, Y. Kitazumi, O. Shirai, K. Kano, J. Electroanal. Chem. 2016, 783, 316-323. 


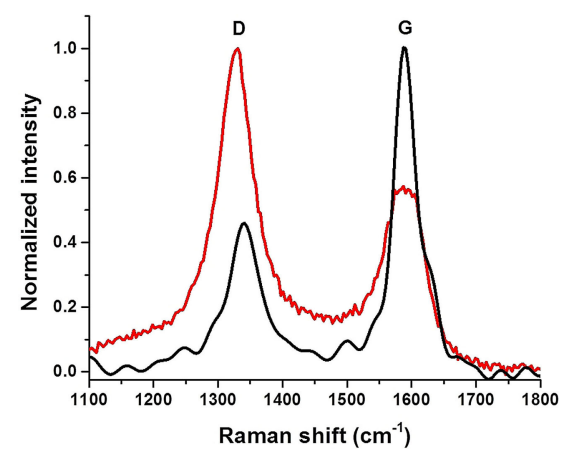

X. Chen, A. J. Gross, F. Giroud, M.

Holzinger, S. Cosnier*

$1-11$

Comparison of Commercial and Lab-Made MWCNT Buckypaper:

Physicochemical Properties and Bioelectrocatalytic $\mathrm{O}_{2}$ Reduction 